BNL-NUREG-72183-2004-CP

\title{
REVIEW OF PRACTICE FOR DEEPLY EMBEDDED/BURIED NPP STRUCTURES SUBJECT TO SEISMIC LOADINGS
}

\author{
J. Xu \\ Brookhaven National Laboratory \\ Upton, New York 11973-5000, USA \\ Tel. 631-344-2183 \\ Fax. 631-344-4255 \\ C, Hofmayer \\ Brookhaven National Laboratory \\ Upton, New York 11973-5000, USA \\ Tel. 631-344-2183 \\ Fax. 631-344-4255
}

\author{
C. Miller \\ Brookhaven National Laboratory \\ Upton, New York 11973-5000, USA \\ Tel. 631-344-2949 \\ Fax. 631-344-4255 \\ H. Graves \\ US Nuclear Regulatory Commission \\ Washington, D.C. 20555-0001, USA \\ Tel. 301-415-5880 \\ Fax. 301-415-4074
}

\begin{abstract}
Motivated by many design considerations, several conceptual designs for advanced reactors have proposed that the entire reactor building and a significant portion of the steam generator building will be either partially or completely embedded below grade. For the analysis of seismic events, the soil-structure interaction (SSI) effect and passive earth pressure for these types of deeply embedded structures will have a significant influence on the predicted seismic response. Sponsored by the US Nuclear Regulatory Commission (NRC), Brookhaven National Laboratory (BNL) is carrying out a research program to assess the significance of these proposed design features for advanced reactors, and to evaluate the existing analytical methods to determine their applicability and adequacy in capturing the seismic behavior of the proposed designs. This paper summarizes a literature review performed by BNL to determine the state of knowledge and practice for seismic analyses of deeply embedded and/or buried (DEB) nuclear containment type structures. Included in the paper is BNL's review of the open literature of existing standards, tests, and practices that have been used in the design and analysis of DEB structures. The paper also provides BNL's evaluation of available codes and guidelines with respect to seismic design practice of DEB structures. Based on BNL's review, a discussion is provided to highlight the applicability of the existing technologies for seismic analyses of DEB structures and to identify gaps that may exist in knowledge and potential issues that may require better understanding and further research.
\end{abstract}

\section{INTRODUCTION}

Over the past three decades or so, extensive research has been performed to study the phenomenon of soil-structure interaction (SSI), and its impact on seismic response of structures, especially for nuclear power plant (NPP) structures. To date, considerable advancement has been made in better understanding the interacting mechanisms associated with SSI [Roesset, 1989], developing analysis methodologies and computer programs for seismic response calculations which incorporate SSI effects, and obtaining much needed field test data from real earthquake events. However, established SSI analysis computer codes used in the nuclear industry have been primarily developed for the current generation of Light Water Reactors (LWRs) and applied to coupled soil-structure models where the structures are founded at or near the ground surface with shallow embedment. Motivated by many design considerations, several conceptual designs for advanced reactors have proposed that the entire reactor building and a significant portion of the steam generator building will be either partially or completely embedded below grade. Locating safety related structures, systems and components (SSC) below grade could be an effective option to address safety and safeguard issues. Hence, from the regulatory point of view, potential seismic issues pertaining to deeply embedded and/or buried (DEB) structures should be addressed. Issues relating to kinematic interaction and seismic induced earth pressure effects may be more important for the DEB structures during seismic events than for nuclear plants founded at or near the ground surface. Furthermore, the methods and computer programs established primarily for the assessment of SSI effects for the current generation of reactors need to be assessed in the light of the DEB NPP structures to determine their applicability and adequacy in capturing the seismic behavior of this class of structures. 
As part of a multi-year research program to develop a technical basis to support the safety evaluation of DEB structures proposed for advanced reactor designs, Brookhaven National Laboratory (BNL) performed a retrospective review of the literature on the seismic response analyses of DEB structures. The types of DEB structures of interest to this study are massive, reinforced concrete structures typically encountered in NPPs (e.g., containments). The literature review is primarily focused on both analytical and experimental treatment of the seismic response analyses of DEB structures. The relevant standards and regulatory guidelines are also reviewed to determine their applicability for performing seismic design and analyses of DEB structures. The insights gleaned from the literature review are used to identify methods, data and computer programs which are capable of addressing SSI effects associated with seismic response analyses of DEB structures, and to identify knowledge gaps and potential issues that may require further investigation.

This paper is organized in four sections. Section 2 provides a retrospective review of the literature with respect to both analytical and experimental treatment of the seismic response analyses of DEB structures. A discussion of the relevant codes, standards, and regulatory guidelines pertaining to the seismic design and analyses for DEB structures is provided in Section 3. Finally, potential issues identified as a result of the review of the open literature with respect to SSI effects for DEB structures are discussed in Section 4.

\section{LITERATURE SURVEY ON THE SEISMIC ANALYSIS OF DEB STRUCTURES}

The DEB structures considered in this survey consist of massive, stiff structures such as large-scale waste storage tanks [Chen, 1975, Uldrich, 1991, Wang, 1995, Houston, 1999], underground nuclear shelters [Baron, 1960, ASCE Manual, 1961], and nuclear power reactor buildings [Masao, 1979, Prato, 1998, Celebi, 1979]. Evaluation of the seismic response and the design of these types of structures require a detailed consideration of SSI effects (kinematic and inertia interactions), and the prediction of dynamic earth pressures which include nonlinear effects developed between structures and surrounding soils when subjected to a strong seismic motion. The main focus of this section is to review the open literature pertaining to the treatment of SSI effects and the analysis methods used for the dynamic analysis of DEB structures subjected to seismic loads.

\section{Impact of SSI Effects on DEB Structures}

Consideration of the SSI phenomenon is usually broken down into kinematic interaction and inertia interaction effects. Kinematic interaction refers to the modification of the freefield seismic waves by the geometry of the embedded portion of a structure and therefore is independent of the inertia properties of the structure, while inertia interaction is associated with the dynamic response of the coupled structure- foundation system which is governed by the inertia properties of the structure and foundation impedance functions. For structures with shallow or surface foundations, their seismic responses are primarily induced by the inertia interaction effect, while the kinematic interaction effect is expected to be the primary contributor to the seismic response of DEB structures.

Kinematic interaction effects are associated with modification of the free-field motions due to the structural rigidity of an embedded foundation or structure. When a train of seismic waves propagates in an obliquely incident direction in the free field, the induced ground motion varies spatially at any instant of time. Since a typical embedded foundation or structure tends to be much stiffer than the surrounding soils, when subjected to a train of seismic waves traversed in an oblique direction, it cannot accommodate such spatial variability of the ground motion. Instead, the embedded structure tends to maintain its geometry and force the surrounding soils to move with it, which leads to modification of the free-field motion (averaging out the spatially variable motions). It is clear that the kinematic interaction is influenced by the size and rigidity, as well as the depth of embedment of a structure. Because of the nature of the problem, the exact solution for the kinematic interaction effect is very complex and difficult to attain. For the analytical solutions available in the literature, only simple geometries were actually considered, namely, circular, rectangular and strip footings; in most cases, an assumption of rigid foundation was used [Aspel, 1976, Wong, 1974, Iguchi, 1982]. In contrast, numerical methods such as finite element and boundary element methods can be more suitable for investigating the kinematic interaction effect [Day, 1977, Roesset, 1995, Romanel, 1993, Murakami, 1987]. This is especially true for deeply embedded structures when wall flexibility is included in the modeling. In these cases numerical approaches clearly exhibit advantages over the analytical solutions [Lysmer, 1999] for computing kinematic interaction effects for a variety of geometries.

Pais and Kausel [Pais, 1985] performed a detailed investigation of the effects of embedment and inclined $\mathrm{SH}$ waves (out-of-plane shear wave) on the kinematic interaction for circular and rectangular foundations. In their study, an approximate formula by Iguchi [Iguchi, 1982], treating the kinematic interaction for embedded rigid foundations of arbitrary shape, was utilized to obtain the kinematic interaction response functions for foundations where the depth of embedment was varied from zero to two times the foundation radius. The study found that in general, the transfer functions are significantly affected by the foundation embedment for the $\mathrm{SH}$ waves that propagate at steep angles, while for shallow $\mathrm{SH}$ waves, the transfer functions are little influenced by the depth of embedment. The embedment usually results in reduction in translational and torsional responses while inducing significant rocking motion, especially for vertically propagating $\mathrm{SH}$ waves. These observations with respect to the embedment 
effects, however, were arrived at based on elastic half-space studies and SH waves. In reality, soils are usually layered with different properties for each layer and earthquake motions may be propagated with a combination of a variety of different body waves ( $\mathrm{P}$ - compressional wave, SV - in-plane shear wave, SH - out-of-plane shear wave) and surface waves (Rayleigh and Love). Further study that encompasses more realistic soil conditions (e.g., layering effect) and other wave patterns needs to be performed to establish an understanding of the kinematic effects that may be unique to these situations.

The effect of embedment on the dynamic response of DEB structures subjected to various seismic waves was also investigated by a number of other authors [Roesset, 1995, Morray, 1975, Dominguez, 1975, Aviles, 1998]. Findings from these studies showed that the embedment effect, as well as the angle of incidence of the traveling waves effect, on the dynamic behavior of an embedded rigid foundation are consistent with the observations made by Pais and Kausel [Pais, 1985]. Roesset also extended his investigation to include the flexibility of the sidewalls [Roesset, 1995], using vertically propagating shear waves. It should be noted that most of the analytical studies were based on the assumption that perfect bond exists between the structure and the surrounding soils. The actual conditions of the backfill soils are much more complex, and slippage and separation between the structure and the soil as well as base uplifting could take place during a seismic motion. These nonlinear effects could also influence the rocking response.

\section{Seismic Induced Dynamic Pressure on DEB Structures}

Much of the past research effort investigating the effect of seismic induced pressures was primarily focused on earth retaining wall structures. Standard evaluation procedures have been established such as ASCE 4-98 [ASCE 4-98, 1998] which requires either an elastic solution [Wood, 1975] or use of the Mononobe-Okabe (M-O) method [Okabe, 1926, Mononobe, 1929] for the calculation of the seismic induced pressures on earth retaining wall structures. The M-O method is based on the Coulomb wedge theory and requires relatively large movement of the wall. The pressure determined by the M-O solution usually represents a lower bound, especially for structural walls which, due to interior walls and slabs, do not exhibit large relative displacement under seismic motions. Potential nonlinear effects due to the soil-wall interface failures were investigated by Nadim and Whitman [Nadim, 1983], and improved subsequently by Siddharthan and Norris [Siddharthan, 1991], to determine the impact on the distribution of the seismic pressures. In addition, simplified approaches were developed [Scott, 1973, Ortigosa, 1991, Veletsos, 1992, 1993, 1994, Richards, 1999] to characterize the seismic induced pressure distribution on retaining structures, and Ostadan and White [Ostadan, 1998] provided an insightful discussion on practical approaches to computing seismic soil pressure in design. In a recent study [Ostadan, in press], a method is proposed which considers all important SSI parameters in determining seismic induced wall pressure distribution, and most importantly, a simple, easily understood computation procedure which requires only a few steps is provided.

No significant U.S. studies could be found in the literature dealing with seismic pressure effects on typical DEB NPP structures. The lack of research investment in this area in the U.S. may be due to the fact that most of the current generation NPPs do not have deeply embedded or buried containment structures. However, in Japan, because of frequent seismic activities, typical NPP reactor buildings tend to be deeply embedded, and consequently significant research effort has been focused on understanding phenomena associated with seismic induced pressure loads and developing the assessment capability for the seismic pressure effects on the embedded portion of a deeply embedded NPP reactor building. Research activities (both analyses and experiments) have been conducted to focus on issues related to the seismic pressure effects which are unique to deeply embedded NPP reactor structures. Field experiments were conducted in Japan for assessing the adequacy of analysis techniques for the seismic pressure effects on deeply embedded NPP structures. In a paper by Narikawa [Narikawa, 1989], a field experiment was described which involved a $1 / 15$ scale reinforced concrete (RC) model of a NPP reactor building instrumented with pressure gauges. According to the paper, many earthquakes have been recorded since December 1984; the maximum ground surface acceleration recorded for these earthquakes ranges from $16 \mathrm{gal}$ to 120 gal [1 gal $\left.=10^{-2} \mathrm{~m} / \mathrm{sec}^{2}\right]$. Parallel to the experimental activities, analyses using 2-D and 3-D finite element models were performed to correlate with test results, therefore validating the adequacy of analytical techniques for predicting the seismic induced earth pressures. Other field test data on the seismic induced pressures of deeply embedded NPP structures were reported by Onimaru [Onimaru, 1995] and Hirota [Hirota, 1992] for the seismic induced earth pressure on underground walls of embedded NPP structures. Large-scale shaking table tests were performed in Japan such as the one reported by Ohtomo [Ohtomo, 2001] for an underground reinforced concrete duct-type NPP structure. These experimental programs conducted in Japan could be used to evaluate and verify the applicability and adequacy of the analytical methods and computer programs with respect to DEB NPP structures. Furthermore, the shaking table tests [Ohtomo, 2001] also permit the study of many non-linear phenomena associated with a DEB NPP structure subjected to large magnitude earthquakes. In addition, effort was also made in Japan to develop simplified, practical methods to account for the seismic induced pressure effects on DEB type NPP structures, such as the simplified method proposed by Nukui [Nukui, 1989] for calculating the seismic induced dynamic pressure distribution for a massive, rigid DEB structure. 


\section{REVIEW OF GUIDANCE DOCUMENTS}

Guidance provided by the ASCE, USNRC, USDOE, and the Japan Electric Association (JEA) related to the design and analysis of buried facilities are reviewed and discussed in this section. The following aspects of the seismic response problem are of primary interest to this study:

- Convolution of the free field motion throughout the soil media

- Interaction of the free field motion with the stiffness and mass characteristics of the structure

- Evaluation of soil pressures acting on the structure as a result of seismic effects.

The review focuses on those aspects of the problem that pertain to the deeply embedded characteristic of the structures of interest.

ASCE 4-98 (Seismic Analysis of Safety-Related Nuclear Structures and Commentary)

ASCE 4-98 [ASCE 4-98, 1998] is a consensus document published by the American Society of Civil Engineers and provides guidance on most aspects relating to the analysis of structures subjected to seismic loading. Requirements contained in this document form the basis for many of the criteria contained in the other guidance documents considered here.

Vertically propagating shear and compression wave models of the soil are generally recommended in ASCE 4 for computing the seismic motion in free field. Non-linear soil characteristics can be included by performing an iterative series of elastic analyses where the soil properties are revised based on the magnitude of the strains found from the prior solution. When there is an indication that the vertically wave propagating model is not appropriate, the use of a $5 \%$ offset in the structure's center of mass from the geometric center of the foundation can be used, together with results obtained using the vertical wave propagation model, to account for the torsional effects that may be introduced by the non-vertical propagation of the free field waves. These torsional effects may be more significant for deeply embedded structures than for the structures of interest to ASCE 4. The propagation of the free field waves is usually based on a linear elastic model of the soil.

Two types of analyses are recommended in ASCE 4 for evaluating the interaction of the free field motion with the structure (SSI): (i) the direct method which requires the development of a combined model for the soil and structure. The model usually consists of finite elements and/or boundary elements. Soil boundaries are placed distant enough from the structure so that the structure's response is not overly influenced by reflections from the boundaries. Free field motions, consistent with the anticipated seismic motion at the foundation elevation, are applied at the boundaries. These motions should be consistent with the soil properties, types of waves propagating during the earthquake, and boundary characteristics. There may be a larger uncertainty in generating these motions for the deeply embedded structures of interest here than for the structures discussed in ASCE 4; and (ii) the impedance method which uncouples the free field from the structure. A solution for the motion of a mass-less rigid foundation (kinematic interaction problem) is first found, given the shape of the foundation and the free field motion. A model of the structure is then connected to the free field with impedance functions (inertial interaction problem) and the foundation motion found from the kinematic interaction problem used as input to the impedance functions. Solutions for impedance functions representing the soil above the roof of a totally buried structure are not available and would need to be developed. Also, impedance functions for the soil along the sidewalls of an embedded structure are uncertain and the effect of the uncertainty increases as the depth of burial increases. ASCE suggests that soil near the top of the embedded depth not be connected to the structure, thereby accounting for some separation of the soil from the structure. Further work is required to determine the extent to which sidewall impedance functions currently in use are applicable to deeply embedded structures.

ASCE 4 recommends that elastic solutions be used to determine wall pressures. An elastic model of the soil is attached to an elastic model of the structure and the pressures determined from the interaction forces between the soil and structure define the wall pressures. This solution may not be valid for those cases where the soil tends to separate from the structure. In these cases the soil tends to bridge over the separation areas thereby decreasing the pressure acting on the wall. The extent to which such bridging can occur is limited by the strength of the soil. Non-linear strength models of the soil are required to account for this effect. The Mononobe-Okabe model is an active soil pressure solution and accounts for the bridging action of the soil and generally results in lower soil pressures than found with elastic models. It should be noted, however, that the development of this bridging action requires sizeable displacements of the wall. It must be determined that the functionality of the wall is not compromised before such solutions can be used. If the separation of the soil from the structure occurs from the soil surface down to some depth, it may be possible that the bridging action of the soil does not reduce the soil pressure. In this case the wall pressures that have been relieved near the surface are transferred down through the soil and may result in higher wall pressures at depth. This case can be considered by uncoupling the soil from the structure near the surface and then using an elastic solution. If this is done the elastic solution will give conservative results provided an appropriate depth of separation is used.

\section{$\underline{\text { U.S. NRC Standard Review Plan (SRP) }}$}


Seismic analysis sections (e.g., Section 3.7.2: Seismic System Analysis) of the US NRC SRP [NUREG-0800, Rev. 2, 1989] are much less prescriptive than ASCE 4. The SRP generally discusses the characteristics of the problem that need to be considered, but does not usually contain specific information describing the models that should be used. There is no special mention of those facilities which are deeply embedded or buried.

The SRP recommends that the seismic response of structures be determined based on either the direct approach, where simultaneous solutions are obtained for the free field and structure, or a substructure approach, where separate solutions are obtained and then coupled together. It is suggested that nonlinear soil properties can be handled by performing iterative solutions with the soil properties for the current iteration based on soil strains found in the prior iteration. In either case, it is required to consider both kinematic and inertial interaction, the potential variation in soil properties, and the potential debonding between the soil and structure. Variation of parameter studies is required to assess the impact of problem uncertainties and when possible the analysis methods are to be qualified by comparison with benchmark problems.

However, the SRP does not contain specific guidance for the calculation of seismic induced soil pressures which is more pertinent to structures that are deeply embedded or buried in the ground. Guidance can be implied in that the same models used to evaluate SSI effects may be applied to compute soil pressures on the exterior walls. The linear elastic models recommended in the SRP for evaluation of SSI effects, however, are known to provide quite conservative estimates of the seismic induced soil pressures. The SRP should include some discussion of different aspects of seismic induced soil pressures and provide recommendations for alternative methods of computing them with models that are less conservative than the linear SSI models.

\section{DOE Guidelines for Buried Waste Tanks}

The US DOE developed guidelines [BNL Report, 1995] that can be used for the analysis and design of buried waste tanks. These tanks are usually completely embedded and often have some soil cover over the top of the tank. The following recommendations contained in the guidelines are of interest to the current study:

-The control point motion should generally be specified at the ground surface. In those cases, however, where a shallow soft surface layer overlies a stiffer soil layer the control point should be specified at the top of the stiffer layer and the input motion given as an equivalent outcrop motion. In either case motions throughout the free field are calculated using standard convolution methods using the vertically propagating shear wave model. The convolution studies are not required when the site is "uniform" (the shear wave velocity of the soil 1 diameter below the foundation is less than 1.5 times the shear wave velocity of the soil above the foundation). In this case, the motion over the depth of embedment can be assumed to be equal to the surface motion. These conclusions were based on the results of parametric studies where properties of the soil column were varied and response spectra derived using these soil columns were compared with response spectra of the input surface motion.

-Soil structure interaction can be done using either the continuum model or the lumped parameter model. It is shown that the neglect of soil structure interaction effects result in less than a $20 \%$ error for facilities located in "uniform" soil, having no soil cover, and having embedment depth to radius ratios less than unity. For these same conditions it is found that soil structure interaction effects reduce the load acting on the facility. This conclusion was also based on comparison of response spectra developed using the "uniform soil" description with response spectra for the surface input motion.

-Impedance functions for the lumped parameter method are based on the assumption that the foundation is rigid as compared to the soil it replaces. This condition is found to be satisfied when the shear stiffness of the foundation is at least three times the stiffness of the soil it replaces. It is also recommended that the lumped parameter method be restricted to those cases where the soil cover is less than one half the foundation radius.

-Kinematic interaction is shown to reduce the response of the facility when the depth of embedment to foundation radius ratio is between 0.5 and 1 , and the depth of soil cover is less than 0.5 times the foundation radius. It is also shown to be conservative to represent the motion input to the base and top of the foundation as the free field motion at the respective depths.

-It is recommended that wall pressures be calculated with elastic models with the possibility of reducing the wall pressure so that the soil stresses are limited by the Coulomb-Mohr soil strength model.

\section{Japanese Guidelines}

Current earthquake engineering practice for Japanese nuclear power plants is described in JEAG 4601-1987, "Technical Guidelines for Aseismic Design of Nuclear Power Plants," published by JEA. The USNRC sponsored BNL to translate this document, which consisted of more than 900 pages of technical material, into English [Park, 1994].

The document discusses the procedures for the selection of the design basis earthquakes (S1 and S2), including the use of past earthquake and micro tremor records and empirical equations for estimating ground motion intensities. It provides a comprehensive description of the requirements for detailing 
the site soil conditions. For buried structures conventional methods of analysis as well as more detailed finite element methods are presented, including items such as settlement induced by liquefaction, buoyancy effects and the evaluation of seismic effects on sidewalls. Procedures for the simplified nonlinear analysis of structures are presented, including empirical equations for the evaluation of shear walls and procedures for evaluating foundation uplifting. Methods to perform soil structure interaction analysis are presented, as well as detailed guidelines and formulas for the seismic analysis of equipment and supports.

In the 1991 Supplement to JEAG 4601, new improvements were made to account for embedment effects. The 1991 Supplement also summarizes the evaluation methods for the earth pressure on underground walls based on recorded pressure data and analyses. To evaluate the long-term pressure, the methods to account for excavation, building design and backfill effects are described. For the earth pressure during earthquakes, analysis limitations as well as the simplified evaluation method of earth pressure based on SSI analysis are described.

\section{POTENTIAL ISSUES RELATED TO DEB STRUCTURES AND CONCLUDING REMARKS}

In this study, a review of literature was performed to determine the extent of the current seismic design and analysis practice applicable to DEB NPP Structures. The literature review has identified extensive research materials which addressed various aspects of seismic analysis and experiments pertaining to DEB structures. Several areas were also identified where potential uncertainties exist in the analytical methods used to evaluate the seismic response of deeply embedded facilities. The major uncertainties found are: the effect of deep embedment on the relative significance of kinematic interaction; the extent to which non-vertically propagating shear waves may be more important for deeply embedded structures than for those with shallow embedment depth; the effect of nonlinear effects (separation of wall and soil and soil properties) on wall pressures; and the impact of deep embedment on the accuracy of side wall impedance functions calculated with standard methods.

The following study is therefore recommended to quantify these uncertainties and to develop criteria required to analyze the seismic response of deeply embedded facilities:
a. Kinematic Interaction vs. depth of burial
b. Effects of non-vertically propagating seismic waves on DEB structures

\author{
c. Wall Pressures and Other Non Linear Effects \\ d. Sidewall Interaction effect
}

Further, as described in this paper, several field and shaking table tests have been performed in Japan on large scale DEB NPP structures. These recorded data are valuable tools and could be used to verify the validity and adequacy of analytical techniques and computer programs for seismic analyses of DEB structures.

\section{DISCLAIMER NOTICE}

This work was performed under the auspices of the U.S. Nuclear Regulatory Commission, Washington, D.C. The findings and opinions expressed in this paper are those of the authors, and do not necessarily reflect the views of the U.S. Nuclear Regulatory Commission or Brookhaven National Laboratory.

\section{REFERENCES}

ASCE Manual, "Design of Structures to Resist Nuclear Weapons Effects," Manual of Engineering Practice No. 42, ASCE, NY, 1961.

ASCE 4-98, “ASCE Standard - Seismic Analysis of Safety Related Nuclear Structures and Commentary on Standard for Seismic Analysis of Safety Related Nuclear Structures," American Society of Civil Engineers, 1998.

Aspel, R.J., et al., "Torsional Response of Rigid Embedded Foundations," Journal of the Eng. Mech. Div., ASCE, vol. 102, No. EM6, pp 957-970, Dec 1976.

Aviles, J., et al., "Effects of Foundation Embedment During Building-Soil Interaction," Earthquake Engineering and Structural Dynamics, 27, 1523-1540, 1998.

Baron, H., et al., "Theoretical Studies on the Ground Shock Phenomena," Report No. SR-19, The MITRE Corporation, 1960 .

BNL report, "Seismic Design and Evaluation Guidelines for The Department of Energy High-Level Waste Storage Tanks and Appurtenances," Prepared for the U.S. Department of Energy, BNL 52361 (rev. 10/95), October 1995.

Celebi, M., et al., "Inelastic Seismic Analysis of Deeply Embedded Reinforced Concrete Reactor Building," 5th Int. Conf. on Structural Mechanics in Reactor Technology, Amsterdam, Netherlands, 1979.

Chen, P. C., et al., "Soil-Structure Interaction of Buried Structures," Structure Design of Nuclear Power Plant Facilities, vol. 1-b, ASCE specialty conf., New Orleans, LA, pp. 10321058, 1975.

Day, S. M., "Finite Element Analysis of Seismic Scattering Problems," Ph.D. Thesis, Univ. of California, San Diego, 1977. 
Dominguez, J., "Response of Embedded Foundations to Traveling Waves,” Research Report R78-24, MIT, 1975.

Hirota, M., "Study of Dynamic Earth Pressure through Observation," Tenth World Conf. on Earthquake Engineering, Balkerma, Rotterdam, 1992.

Houston, T. W., et al., "Seismic Evaluation of A Fuel Facility in A Soil Layer over Rock," ASME Pressure Vessel and Piping Conf., Boston, MA, July 1999.

Iguchi, M., “An Approximate Analysis of Input Motions for Rigid Embedded Foundations," Trans. of Architectural Inst. Of Japan, No. 315, pp. 61-75, May 1982.

Japan Electric Association (JEA), "Technical Guidelines for Aseismic Design of Nuclear Power Plants," JEAG 4601-1991 Supplement (in Japanese).

Lysmer, J., et al., 1999, "SASSI2000 - Theoretical Manual," Revision 1, Geotechnical Engineering, University of California, Berkeley.

Masao, T., et al., "Earthquake Response of Nuclear Reactor Building Deeply Embedded in Soil," 5th Int. Conf. on Structural Mechanics in Reactor Technology, Amsterdam, Netherlands, 1979.

Mononobe, N., et al., "On the Determination of Earth Pressures during Earthquakes," Proc. World Eng. Conf., 9, 176, 1929.

Morray, J. P., "Kinematic Interaction Problem of Embedded Circular Foundations," M.S. Thesis, Department of Civil Engineering, MIT, 1975.

Murakami, H., et al., "Earthquake Response Analyses of SoilStructure System Considering Kinematic Interaction," the 9th Int. Conf. on Structural Mechanics in Reactor Technology, 1987.

Nadim, F., et al., "Seismically Induced Movement of Retaining Walls,” J. Geotech. Eng. Conf., ASCE, 109(7), 915-931, 1983.

Narikawa, M., et al., "Experimental and Analytical Study on Earth Pressure of an Embedded Building Model," 10th Int. Conf. on Structural Mechanics in Reactor Technology, k1, Anaheim, CA, 1989.

Nukui, Y., et al., "Fundamental Characteristics and Simplified Evaluation Method of Dynamic Earth Pressure," 10th Int. Conf. on Structural Mechanics in Reactor Technology, Anaheim, k1, CA, 1989.

Ohtomo, K., et al., "Research on Streamlining Seismic Safety Evaluation of Underground Reinforced Concrete Duct-Type Structures in Nuclear Power Stations - Part 2, Experimental
Aspects of Laminar Shear Sand Box Excitation Tests with Embedded RC Models," 16th Int. Conf. on Structural Mechanics in Reactor Technology, k1, Washington, DC, 2001.

Okabe, S., "General Theory of Earth Pressure," J. Japanese Soc. Of Civil Engrs., Tokyo, 12(1), 1926.

Onimaru, S., et al., "Study of Dynamic Earth Pressure Acting on a Deeply Embedded Structure," 13th Int. Conf. on Structural Mechanics in Reactor Technology, k1, Porto Alegre, Brazil, 1995.

Ortigosa, P., et al., "Seismic Earth Pressures against Structures with Restrained Displacements," Proc., 2nd Int. Conf. on Recent Adv. in Geotech. Earthquake Eng. and Soil Dyn., 621$628,1991$.

Ostadan, F. and White, W. H., "Lateral Seismic Soil Pressure: An Updated Approach," 1st US-Japan SSI Workshop, Menlo Park, California, September 22-23, 1998.

Ostadan, F. and Penzien, J., "Seismic Soil Pressure for Building Walls-An Updated Approach," Submitted to 11th ICSDEE Conference, January 2004.

Pais, A., et al., "Stochastic response of foundations," Report No. R8506, MIT, Massachusetts, 1985.

Park, Y.J. and Hofmayer, C.H., "Technical Guidelines for Aseismic Design of Nuclear Power Plants - Translation of JEAG 4601-1987,’ NUREG/CR-6241, June 1994.

Prato, C.A. et al., "Full Scale Dynamic Tests of Atucha II NPP," Nuclear Engineering and Design 179, pp. 225-243, 1998.

Richards, R., et al., "Seismic Earth Pressure on Retaining Structures," J. of Geotech. And Geoenv. Eng., ASCE, 771, 1999.

Roesset, J.M., "Perspectives on Soil Structure Interaction Analysis," Proceedings of EPRI/NRC/TPC Workshop on Seismic Soil-Structure Analysis, Lotung, Taiwan," Vol. 1, EPRI NP-6154, March 1989.

Roesset, J.M., "Seismic Response of Structures on Embedded Foundations," Advances in Earthquake Engineering, v2, Earthquake Resistant Engineering Structures, pp. 19-34, Computational Mechanics Publisher, Southampton, Engl., 1995.

Romanel, C., et al., "Analysis of Deeply Embedded Structures in a Layered Half-Space," Proceedings of the 12th International Conf. On Offshore Mechanics and Artic Engineering, ASME, Glasgow, Scotland, 1993. 
Scott, R.F., "Earthquake-Induced Pressures on Retaining Walls," Proc., 5th World Conf. On Earthquake Eng., Int. Assn. Of Earthquake Eng., Tokyo, 2, 1611-1620, 1973.

Siddharthan, R., et al., "On the Seismic Displacement Response of Rigid Retaining Walls," Soil and Foundations, 31(2), 51-64, 1991.

Uldrich, E.D., et al., "Seismic Analysis of the ICPP High Level Liquid Waste Tanks and Vaults," Third DOE Natural Phenomena Hazards Mitigation Conf., St. Louis, MO., Oct. 1991.

NUREG-0800, Revision 2, 1989, "Standard Review Plan," Office of Nuclear Reactor Regulation, U.S. Nuclear Regulatory Commission.

Veletsos, A.S., et al., "Dynamic Modeling and Response of Soil-Wall Systems," J. Geotech. Eng., ASCE, 120(12), 21552179, 1994.

Wang, C.Y., "Structural and Seismic Analyses of Waste Facility Reinforced Concrete Storage Vaults," ASME Pressure Vessel and Piping Conf., Honolulu, Hawaii, July 1995.

Wong, H. L. et al., "Interaction of a Shear Wall with the Soil for Incident Plane SH-waves: Elliptical Rigid Foundation," Bull. Seism. Soc. Amer., vol. 64, pp. 1825-1842, 1974.

Wood, J.H., "Earthquake Induced Pressures on a Rigid Wall Structure," Bull. of New Zealand Nat. Soc. for Earthquake Eng., 8(3), 175-186, 1975. 